\title{
Impact of the Covid-19 Pandemic on Women's Health in Brazil
}

\author{
Lander Dos Santos (1D) \\ Kely Paviani Stevanato (iD) \\ Igor Roszkowski ${ }^{1}$ \\ Raíssa Bocchi Pedroso' \\ Fernando Castilho Pelloso ${ }^{2}$ \\ Karina Maria Salvatore Freitas (iD ${ }^{3}$ \\ Maria Dalva de Barros Carvalho' \\ Sandra Marisa Pelloso ${ }^{1,3}$ \\ 'State University of Maringá, Maringá, \\ Parana, Brazil; ${ }^{2}$ Federal University of \\ Paraná, Curitiba, Parana, Brazil; \\ ${ }^{3}$ Faculdade Ingá, Maringá, Parana, Brazil
}

Correspondence: Kely Paviani Stevanato Program in Health Science from the State University of Maringá, Colombo Avenue, Maringá, 5790, Paraná, Brazil

$\mathrm{Tel} / \mathrm{Fax}+554430 \mathrm{I}$ I-4040

Email kelystevanato@gmail.com
Purpose: The aim is to verify the impact of the Covid-19 pandemic on women's healthcare and medical assistance in Brazil.

Patients and Methods: This exploratory cross-sectional study evaluated a non-probabilistic sample of women above 20 years old, carried out between August and September of 2020, through a snowball sampling using a Google Forms application.

Results: From a total of 2495 women, more than $70 \%$ have not been screened for cervical cancer (77.8\% of 2244 women aged for screening), and more than $80 \%$ have not been screened for breast cancer $(80.2 \%$ from 1325 women aged for mammography) during the pandemic. Also, 55.2\% of the women did not undergo routine blood tests during the same period. The most frequent reasons for not performing screening and routine tests were: they were up to date; fear of contracting Covid-19; they decided to postpone it until after the end of the pandemic; they were unable to schedule the appointment at the healthcare center for whatever reason; and the healthcare center was only attending Covid-19 patients. Women with no comorbidities have performed significantly more mammograms and routine blood tests than women with comorbidities. In addition, women with comorbidities who were used to perform periodic medical follow-up have done it substantially more than women with no comorbidities during the pandemic.

Conclusion: As observed, there was a significant decrease in women's access to the healthcare system during this pandemic. Many participants reported that they had not attended any screening tests, and some reasons included fear of getting infected and due to the public measures of social distancing. The consequences are late diagnoses and a worse prognosis. It might impact the healthcare systems around the world in the next few years. Further studies should be done to follow these consequences.

Keywords: health impact assessment, Sars-Cov-2 infection, pandemic, women's health

\section{Introduction}

The whole world is facing a devastating coronavirus pandemic. The World Health Organization called it a Global Health Crisis and a public emergency. Data collected on September 19th, 2021, indicated almost 219 million cases and 4550 million deaths ongoing worldwide. ${ }^{1}$

In Brazil, coronavirus has spread rapidly, and the situation has become tragic. Brazil registered the second-highest number of infections and deaths caused by Covid-19 in the world. Until recently, there were 21.2 million cases and 591 million deaths from Covid-19 nationwide. The incidence was 10,102.6 cases per 100,000 inhabitants, the mortality rate was 281.0 per 100,000 inhabitants, and the mortality rate was $2.8 \%{ }^{2}$ 
This Pandemic has severe consequences for society, not only as a fatal disease but also as a financial crisis, mainly for underdeveloped economies. Furthermore, social distancing - one of the essential restrictive measures to prevent Covid-19 from spreading - changed the flow in most activities, especially in the health systems.

In the Brazilian public health system, women are considerably more used to looking for frequent medical appointments than men, demonstrating how much they care about themselves and their family's health status. ${ }^{3}$ However, many of the permanent public health programs and promotion and prevention activities were interrupted due to the Pandemic.

It is known that women have worse results in some health conditions, such as asthma, diabetes, and myocardial infarction, ${ }^{4}$ so less access can lead to even more health disparities. Therefore, it is crucial to maintain open access to programs such as vaccines, birth control, preventative screening tests, medications, and treatments. Given this context, this study aims to verify the impact of the Covid-19 Pandemic on Women's healthcare and medical assistance in Brazil.

\section{Patients and Methods}

This exploratory cross-sectional study evaluated a nonprobability sampling of women aged above 20 years old between August and September 2020. Researchers developed a survey to collect data first applied to a pilot group of 20 random women to validate the survey (this group was not included in the final sample). A Google Forms application hosted the survey and stored the data.

To participate in the survey, the women had to read and agree to the informed consent on the first page. The study was conducted in accordance with the Declaration of Helsinki and approved by the Research Ethics Committee of the Faculdade Ingá, under protocol number 4.276.900.

Researchers created a web link to access the survey and shared it throughout social media for 60 days to sample the survey. First, it started from the researcher's media groups and their acquaintances, and then, everyone could share it. This technique is known as snowball sampling, which generates a chain of participants. As inclusion criteria, women over 20 years old who agreed to respond to the survey were included in this research.

The descriptive analysis was performed using Microsoft Excel 2019, and the Statistic Software (version 12, Starsoft, Tulsa, USA) was used for statistical analysis.
Pearson's Chi-square tests were used to determine the association between the different variables, and Binomial logistic regression was calculated to understand the impact of the variables on the outcome. Values of $p<0.05$ were considered significant.

\section{Results}

The survey gathered 2495 answers from women over 20 years old. The main characteristics of the women who answered the survey are presented in Figure 1. Most of them were from 25 to 44 years old (1369/54.87\%), selfidentified as white $(1923 / 77.1 \%)$, catholic $(1351 / 54.1 \%)$, graduated on higher education $(1779 / 71.3 \%)$, married $(1751 / 70.2 \%)$, nullipara $(1018 / 40.8 \%)$ of those who have already given birth, the majority had two children (724/ $29 \%)$. Only $1.6 \%(n=41)$ were pregnant at the moment they answered the survey.

About $33.3 \%$ declared to be head of household $(\mathrm{n}=832)$, and more than a half $(1726 / 69.2 \%)$ are working women. From these, $34.8 \%$, $(n=600)$ had a governmental job, while 33\% $(n=570)$ had a formal non-government job. When asked about job stability, $57.4 \%(\mathrm{n}=990)$ worked for more than five years at the same place with a daily journey of up to 8 hours a day $(727 / 42.1 \%)$, and $55.5 \%(n=1329)$ declared to earn up to 5000 reais (Almost 1000 American dollars), monthly (Figure 1).

Only $5.7 \%$ declared to be smokers $(n=141)$, and they usually consumed less than one pack a day, and, from those, 59.6\% $(\mathrm{n}=84)$ have reported increasing their tobacco consumption during the Pandemic.

About their health conditions (Figure 2), only 52.14\% $(n=1301)$ said to have one $(n=916)$ or more than one $(\mathrm{n}=385)$ comorbidities. Allergic rhinitis was the most prevalent health condition reported $(842 / 33.7 \%)$, followed by high blood pressure $(317 / 12.7 \%)$ and thyroid illness (268/10.7\%).

About cervical cancer prevention, 89.9\% $(\mathrm{n}=2244)$ had already performed it at least once, and of those, 58.8\% $(n=1140)$ had done it in less than a year. However, when asked if they had done cervical cancer prevention during the Covid-19 Pandemic, 77.8\% ( $\mathrm{n}=1746)$ answered no. The reasons for not doing the cervical cancer screening were: they were up to date $(731 / 32.6 \%)$; fear of getting sick by Covid-19 (298/13.3\%); they had decided to postpone it until after the end of the Pandemic (256/11.4\%); they were unable to schedule the appointment at the Healthcare center for wherever reason $(109 / 4.9 \%)$ and, 


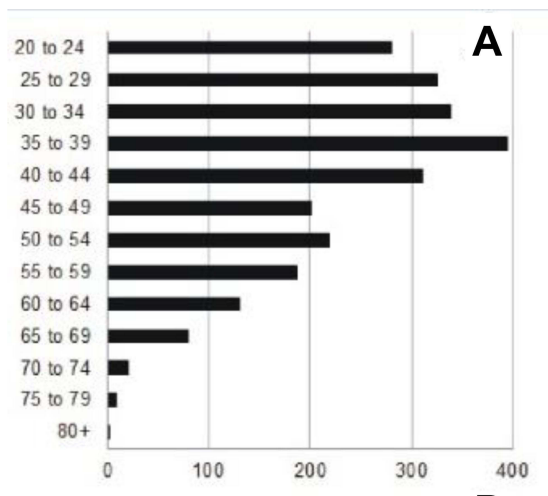

D
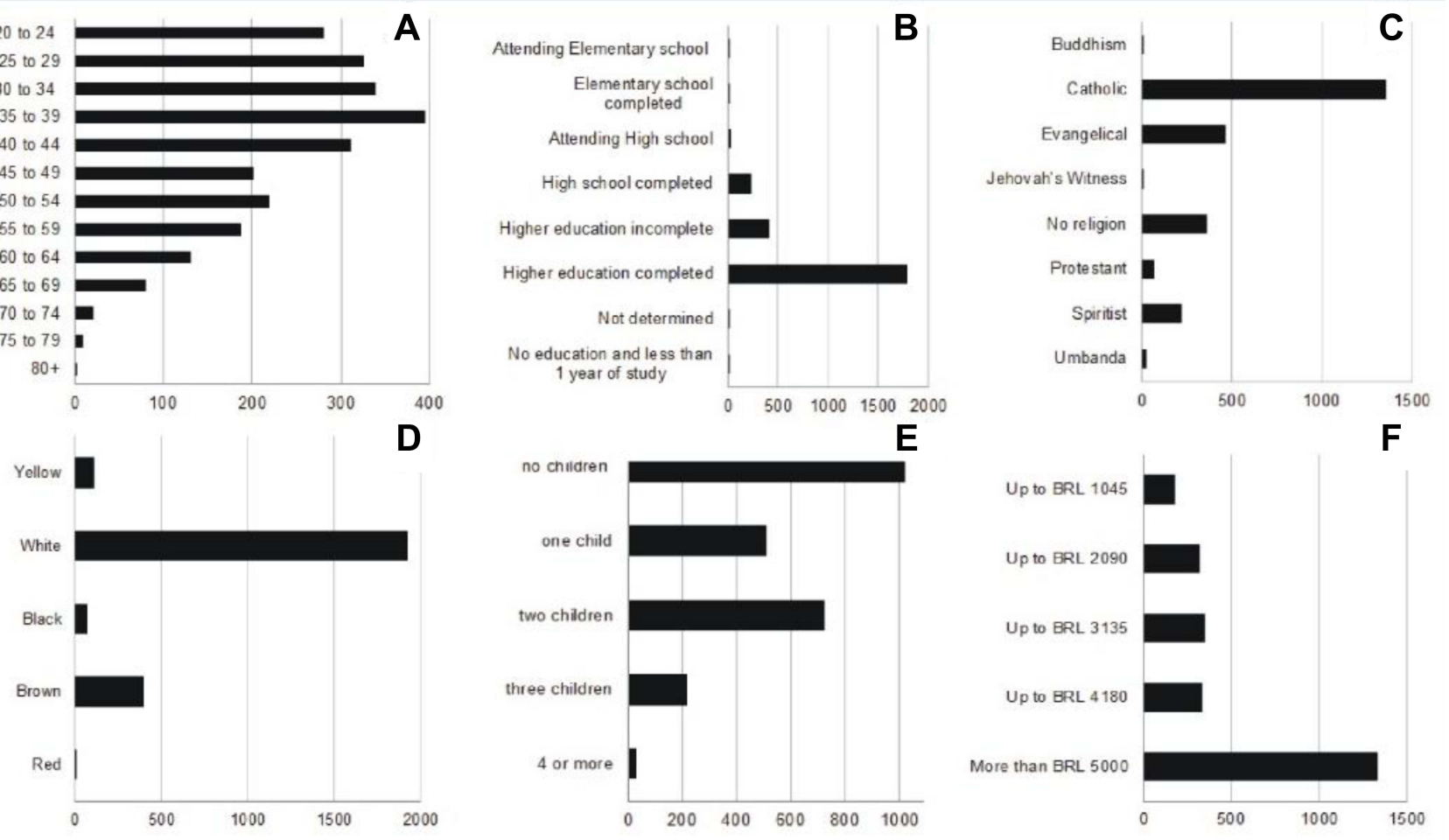

Figure I Distribution of the responses of the main characteristics of the women from the survey (2495 women). (A) age distribution, (B) Level of education, (C) Religion, (D) self-identified skin color, (E) Number of children, (F) Monthly income, in Brazilian reais (BRL).

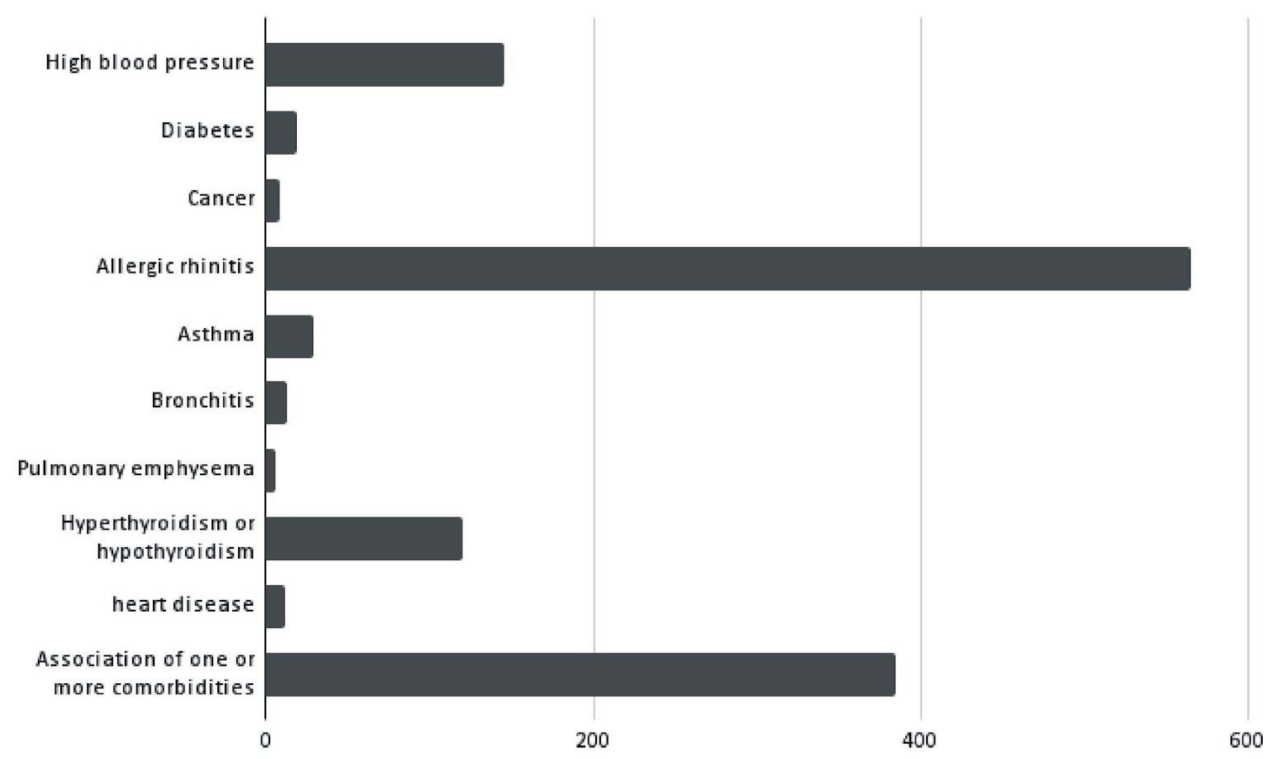

Figure 2 Self-reported illnesses from women who answered the survey. From 2495 reissuing cervical screening invitations answers, II 94 (47.85\%) were not applicable. Thus, at least $130 \mathrm{I}$ women reported suffering illnesses; of them, 916 (70.40\%) had only one of those in the graphic, and 385 (29.59\%) had an association of one or more.

$2.9 \%(n=64)$ answered that the healthcare center was assisting only Covid-19 patients.

About breast cancer prevention, 53.1\% $(\mathrm{n}=1325)$ had already had a mammogram at least once, and from those, $48.5 \%(n=642)$ had done it in less than a year. However, when asked if they had done a mammogram during the Covid-19 Pandemic, 80.2\% $(n=1063)$ answered no. The reasons for not doing it were: they were up to date (501/ $37.8 \%$ ); fear of getting sick by Covid-19 (160/12.1\%); they had decided to postpone it until after the end of the 
Pandemic (129/9.7\%); they were not able to schedule the appointment at the Healthcare center (50/3.8\%), and $2.4 \%$ $(n=32)$ answered that the healthcare center was assisting only Covid-19 patients.

About a routine blood test (for diabetes or hypercholesterolemia, for example), only 44.8\% $(n=1118)$ had done it during the Pandemic. The reasons for the 55.2\% $(n=1377)$ that did not undergo were: they were up to date $(505 / 20.2 \%)$; fear of getting sick by Covid-19 (288/ $11.5 \%)$; they had decided to postpone it until after the end of the Pandemic (253/10.1\%), they were not able to schedule the appointment at the Healthcare center $(82 / 3.3 \%)$, and $2.5 \%(n=83)$ answered that the healthcare center was assisting only Covid-19 patients.

About ongoing illness treatment or medical follow-up, $45.9 \%(n=1146)$ answered yes, and 61.9\% $(n=709)$ said they could perform their treatment as often as before.

About social distancing, the majority, $85.3 \%(n=2127)$, reported doing it, but $49.4 \%(n=1233)$ of them said they had problems staying at home. The reasons were: the distance from family and friends (1571/63\%); stress due to isolation $(852 / 34.1 \%)$; realizing that others did not respect the social distancing $(651 / 26.1 \%)$; doing essential activities (602/24.1\%); concern for the future of the Covid-19 Pandemic (599/24\%); financial needs (529/ $21.2 \%)$; concern about their jobs $(379 / 15.2 \%)$ and increasing housework (352/14.1\%).

Only $6.3 \%(n=158)$ reported to have been infected by Covid-19, and the most common symptoms were headache
(118/74.7\%); body pain (97/61.4\%); loss of smell and taste (93/58.9\%); throat pain (75/47.5\%); cough (74/46.8\%); dyspnea (59/37.3\%) and fever (55/34.8\%). About the fear of dying from the Covid-19 infection, 43\% $(n=68)$ said they were afraid.

Women with no comorbidities had performed significantly more mammograms $(\mathrm{p}=0.029)$ and routine blood tests $(p=0.001)$ than women with comorbidities but, women with comorbidities who were used to perform periodic medical follow-up had done it significantly more than women with no comorbidities $(p=0.031)$ during the Pandemic (Table 1).

Statistical significance was found between practicing social distancing and not performing cervical cancer prevention $(\mathrm{p}=0.019)$ (Table 2$)$.

Binomial logistic regression showed how age, schooling, and income could determine women's health prevention during the Covid-19 Pandemic. Only cervical cancer screening and routine blood tests were statistically significant; it indicated an influence of age in cervical cancer screening $(p<0.001)$ and age $(p<0.001)$ and income $(\mathrm{p}<0.001)$ on routine blood tests. During the Pandemic, those who had done more health screening tests were women aged between 25 to 44 years and those with higher salaries. Schooling did not influence it.

\section{Discussion}

The Covid-19 Pandemic collapsed the Healthcare system, andmedical assistance struggled in many parts of the

Table I The Association of Having Comorbidities and Undergoing Cervical Cancer and Breast Cancer Prevention, Routine Blood Tests, and Medical Assistance

\begin{tabular}{|c|c|c|c|}
\hline & Comorbidity $N=$ I I 87 & No Comorbidity $n=\mid 308$ & \\
\hline $\begin{array}{l}\text { Cervical cancer prevention } \\
\text { Yes } \\
\text { No }\end{array}$ & $\begin{array}{l}234 \text { (19.7\%) } \\
953(80.3 \%)\end{array}$ & $\begin{array}{c}264(20.2 \%) \\
1044(79.8 \%)\end{array}$ & $\begin{array}{c}X^{2}=0.08 \\
D F=1 \\
P=0.769\end{array}$ \\
\hline $\begin{array}{l}\text { Breast cancer prevention } \\
\text { (Mammography) } \\
\text { Yes } \\
\text { No }\end{array}$ & $\begin{array}{c}108(9.1 \%) \\
1079(90.9 \%)\end{array}$ & $\begin{array}{l}\text { I } 54 \text { (II.8\%) } \\
\text { II } 54 \text { (88.2\%) }\end{array}$ & $\begin{array}{c}X^{2}=4.73 \\
D F=I \\
p=0.029 *\end{array}$ \\
\hline $\begin{array}{l}\text { Routine blood tests } \\
\text { Yes } \\
\text { No }\end{array}$ & $\begin{array}{l}492(41.4 \%) \\
695(58.6 \%)\end{array}$ & $\begin{array}{l}626(47.9 \%) \\
682(52.1 \%)\end{array}$ & $\begin{array}{c}X^{2}=10.33 \\
D F=1 \\
p=0.001 *\end{array}$ \\
\hline $\begin{array}{l}\text { Medical Assistance } \\
\text { Yes } \\
\text { No }\end{array}$ & $\begin{array}{l}253(65.7 \%) \\
129(34.3 \%)\end{array}$ & $\begin{array}{l}456(59.7 \%) \\
308(40.3 \%)\end{array}$ & $\begin{array}{c}X^{2}=4.62 \\
D F=1 \\
p=0.03 I^{*}\end{array}$ \\
\hline
\end{tabular}

Note: $* \mathrm{p}<0.05 ; \mathrm{X}^{2}=$ Chi-square test. 
Table 2 The Association Between Practicing or Not Social Distancing and Undergoing Cervical Cancer and Breast Cancer Prevention, Also Routine Tests and Medical Assistance

\begin{tabular}{|c|c|c|c|}
\hline & $\begin{array}{l}\text { Practiced Social Distancing } \\
\qquad N=2 \text { | } 27\end{array}$ & $\begin{array}{l}\text { Did Not Practice Social } \\
\text { Distancing } n=368\end{array}$ & \\
\hline $\begin{array}{l}\text { Cervical cancer prevention } \\
\text { Yes } \\
\text { No }\end{array}$ & $\begin{array}{c}408(19.2 \%) \\
1719(80.4 \%)\end{array}$ & $\begin{array}{c}90(24.5 \%) \\
278(75.5 \%)\end{array}$ & $\begin{array}{c}X^{2}=5.46 \\
D F=1 \\
P=0.019 *\end{array}$ \\
\hline $\begin{array}{l}\text { Breast cancer prevention } \\
\text { (Mammography) } \\
\text { Yes } \\
\text { No }\end{array}$ & $\begin{array}{c}227(10.7 \%) \\
1900(89.3 \%)\end{array}$ & $\begin{array}{c}35(9.5 \%) \\
333(90.5 \%)\end{array}$ & $\begin{array}{c}X^{2}=0.45 \\
D F=1 \\
p=0.502\end{array}$ \\
\hline $\begin{array}{l}\text { Routine blood tests } \\
\text { Yes } \\
\text { No }\end{array}$ & $\begin{array}{l}950(44.7 \%) \\
\mathrm{I} I 77(55.3 \%)\end{array}$ & $\begin{array}{l}168(45.7 \%) \\
200(54.3 \%)\end{array}$ & $\begin{array}{c}X^{2}=0.12 \\
D F=1 \\
p=0.724\end{array}$ \\
\hline $\begin{array}{l}\text { Medical Assistance } \\
\text { Yes } \\
\text { No }\end{array}$ & $\begin{array}{l}610(61.7 \%) \\
379(38.3 \%)\end{array}$ & $\begin{array}{l}99(63.1 \%) \\
58(36.9 \%)\end{array}$ & $\begin{array}{c}X^{2}=0.10 \\
D F=1 \\
p=0.741\end{array}$ \\
\hline
\end{tabular}

Note: ${ }^{*}<0.05 ; \mathrm{X}^{2}=$ Chi-square test.

world, increasing mortality. Moreover, studies have shown disruption even in consolidated healthcare centers, challenging the whole system, including chronic disease prevention programs. ${ }^{5}$

The Pandemic was responsible for decreasing the demand for medical assistance, mainly screening and prevention. Some reasons were the sanitary measures to break the spread of Covid-19, such as social distancing and lockdowns. However, this scenery also impaired oncological treatments, and patients have faced difficulties coming to appointments and receiving proper treatment. ${ }^{6}$

This study showed a significant decrease in women's access to the healthcare system during this Pandemic. Most of the participants reported they had not attended any screening tests. The main reasons were fear, problems scheduling a medical appointment, interruption of the assistance in healthcare centers, and the lockdown.

Those who practiced social isolation attended fewer cervical cancer screening tests than those who did not. It could be related to fear, anger, sadness, worry, and frustration, even more than limited access to medical assistance. Strategies to postpone the Papanicolaou test could be acceptable considering the need to increase physical distance. ${ }^{7,8}$ The problem would not only be because of a late diagnosis, but it could also impact the recruitment of newly-screened women. ${ }^{5}$

Cervical cancer screening was interrupted around the world. For example, England's Public Health System suspended it from April 2020 to reduce contamination risks. ${ }^{9}$
Oncologists worldwide reported changes in their medical practices, mainly in choosing new priorities and protocols, expecting to reduce patients' number of visits to the hospital, hospitalization time, and treatments. ${ }^{10}$

The interruption or delay of the screening tests due to the Pandemic could make women forget the importance of paying attention to the prevention of breast and cervical cancer and other chronic diseases. ${ }^{11}$

Breast cancer screening tests (mammography) have also decreased significantly in the participants of this study. The main reasons for that were feelings of fear, incapacity of scheduling an appointment, assistance interruption in healthcare centers, and lockdown. In addition, women have preferred to delay the screening to the end of the Pandemic. In Michigan, USA, a recent study showed similar results: a rapid decrease in the screening tests for breast, cervical, uterus, and colon cancer. ${ }^{12}$

Even though Covid-19 is a threat to the healthcare system, which was focused on fighting against the virus, cancer also has a high mortality rate, and it needs early diagnosis and treatment, not to be left alone. ${ }^{13}$

On the one hand, women at low risk for breast cancer could have a minor impact if the screening is delayed ${ }^{14}$ on the other hand, a late diagnosis affects the prognosis of high-risk women seriously. ${ }^{15}$ However, other authors shared the same results; fewer breast cancer screening tests have been performed during the pandemic. ${ }^{16}$ Early diagnosis and treatment are fundamental to overcoming cancer. ${ }^{5}$ 
There was no interruption in breast cancer screening in Taiwan, but they reported $22 \%$ fewer mammograms than the year before. It happened due to limited access to the health system, and they did not intensify it as they used to before the Pandemic. ${ }^{17}$ The USA interrupted screening tests like mammographies, and they changed some treatment protocols, working outflow, continuing education, research, and resources. The results have not been published yet. ${ }^{18}$

A significant group of this study's participants had some comorbidities like hypertension, diabetes, hypothyroidism, asthma, and dyslipidemia, and they sought medical assistance regularly before the Pandemic. Still, after that, they could not do it as they used to. Nevertheless, this group has attended more than those who had no comorbidities. Indian researchers have shared similar results, and for them, to neglect attention to chronic diseases could lead to several damages and more deaths than the Pandemic could do. ${ }^{19}$ One limitation of this study is that it was performed at the end of 2020, a critical time, but not as severe as the first semester of 2021. Social media like WhatsApp and Facebook were essential for the development of this research.

\section{Conclusion}

It is too soon to determine the real impact of the Covid-19 Pandemic on Women's health; most consequences would come in the middle and long term. Nevertheless, it was possible to evaluate the Pandemic's impact on women's access to screening tests. This study results showed a significant decrease in women's access to the healthcare system during this Pandemic. Many participants reported they had not attended any screening tests and some reasons included fear of getting infected and due to the public measures of social distancing. The consequences are late diagnoses and a worse prognosis. It might impact the Healthcare systems around the world in the next few years. Further studies should be done to follow these consequences.

\section{Acknowledgments}

The Coordination for the Improvement of Higher Education Personnel Brazil (CAPES) supported this study.

\section{Disclosure}

The authors report no conflicts of interest.

\section{References}

1. Paho. Pan American Health Organization. Daily COVID-19 Update; 2021. Available from: https://www.paho.org/bra/index.php?option= com_content\&view $=$ article $\&$ id $=6101$ : covid $19 \&$ Itemid $=875$. Accessed March 18, 2021.

2. Brazil. Coronavirus panel; 2021. Available from: https://covid.saude. gov.br/. Accessed March 18, 2021.

3. Costa-Junior FM, Couto MT, Maia ACB. Gender and health care: the point of view of professionals working in hospital and outpatient settings. Sex Salud Soc. 2016;23:97-117.

4. Connor J, Madhavan S, Mokashi M, et al. Health risks and outcomes that disproportionately affect women during the Covid-19 pandemic: a review. Soc Sci Med. 2020;266:113364. doi:10.1016/j. socscimed.2020.113364

5. Feletto E, Grogan P, Dickson C, et al. How has COVID-19 impacted cancer screening? Adaptation of services and the future outlook in Australia. Public Health Res Pract. 2020;30(4):3042026. doi:10.17061/phrp3042026

6. The Lancet Oncology. COVID-19: consequências globais para a oncologia. Lancet Oncol. 2020;21(4):467. doi:10.1016/S1470-2045 (20)30175-3.

7. American Society of Clinical Oncology. ASCO coronavirus resources; 2020. Available from: https://www.asco.org/asco-corona virus-information. Accessed March 18, 2021.

8. ASCCP. Interim guidance for timing and treatment procedures for patients with abnormal cervical screening tests; 2021. Available from: https://www.asccp.org/covid-19-resources. Accessed March 18, 2021.

9. Merrifield N. NHSE to start issuing cervical screening invitations again from this month. PULSE Magazine; 2020. Available from: http://www.pulsetoday.co.uk/clinical/clinical-specialties/cancer/nhseto-start-issuing-cervical-screening-invitations-again-from-this-month/ 20040892.article. Accessed March 18, 2021.

10. Martinelli F, Garbi A. Change in practice in gynecologic oncology during the COVID-19 Pandemic: a social media survey. Int J Gynecol Cancer. 2020;30(8):1101-1107. doi:10.1136/jigs-2020-001585

11. Câmara de Notícias Agency. Secretariat for Women assesses the impact of the pandemic on the treatment of breast cancer in the Brazilian Health System. 2020. Available from: https://www. camara.leg.br/noticias/697629-secretaria-da-mulher-avalia-impactoda-pandemia-no-tratamento-do-cancer-de-mama-no-sus/. Accessed March 19, 2021.

12. Gorin SS, Jimbo M, Heizelman R, et al. The future of cancer screening after COVID-19 may be at home. Cancer. 2020;17(4):498-503.

13. Carneiro MM. Women's health during the COVID-19 pandemic: new roles and views in health care. Women Health. 2020;60(8):849-850. doi:10.1080/03630242.2020.1789263

14. Trentham-Dietz A, Kerlikowske K, Stout NK, et al. Tailoring breast cancer screening intervals by breast density and risk for women aged 50 years or older: collaborative modeling of screening outcomes. Ann Intern Med. 2016;165(10):700-712. doi:10.7326/M16-0476

15. Unger-Saldaña K, Miranda A, Zarco-Espinosa G, et al. Health system delay and its effect on clinical stage of breast cancer: a multicenter study. Cancer. 2015;121(13):2198-2206. doi:10.1002/cncr.29331

16. Song H, Bergman A, Chen AT, et al. Disruptions in preventive care: mammograms during the COVID-19 Pandemic. Health Serv Res. 2021;56(1):95-101. doi:10.1111/1475-6773.13596

17. Tsai HY, Chang YL, Shen CT, et al. Effects of the COVID-19 pandemic on breast cancer screening in Taiwan. Breast. 2020;54:52-55. doi:10.1016/j.breast.2020.08.014

18. Freer PE. The impact of the COVID-19 pandemic on breast imaging. Radiol Clin North Am. 2021;59(1):1-11. doi:10.1016/j. rcl.2020.09.008

19. Chalasani M, Nasir K, Gupta MD, et al. The Covid-19 pandemic and India's cardiovascular disease burden: finding the right balance. Indian J Med Ethics. 2020:1-3. doi:10.20529/IJME.2020.059. 


\section{Publish your work in this journal}

The Journal of Multidisciplinary Healthcare is an international, peerreviewed open-access journal that aims to represent and publish research in healthcare areas delivered by practitioners of different disciplines. This includes studies and reviews conducted by multidisciplinary teams as well as research which evaluates the results or conduct of such teams or healthcare processes in general. The journal covers a very wide range of areas and welcomes submissions from practitioners at all levels, from all over the world. The manuscript management system is completely online and includes a very quick and fair peer-review system. Visit http://www.dovepress.com/testimonials. php to read real quotes from published authors. 